ISSN 1518-3483

Licenciado sob uma Licença Creative Commons

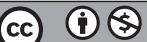

\title{
Educando a sensibilidade: a puericultura como alicerce da moral e do trabalho na Escola Maternal da Sociedade de Socorro aos Necessitados (Curitiba, 1928-1944)
}

\author{
Educating the sensitivity: childcare as \\ foundation of moral and labour \\ at the Escola Maternal da Sociedade \\ de Socorro aos Necessitados \\ (Curitiba, 1928-1944)
}

Keli Fernanda Rucco Turina ${ }^{[a]}$, Marcus Aurelio Taborda de Oliveira ${ }^{[b]}$

[a] Mestre em Educação em História e Historiografia da Educação da Universidade Federal do Paraná, Curitiba, Paraná - Brasil, e-mail: fernandaturina@gmail.com

[b] Pós-doutor pela Facultad de Educación da Universidad de Murcia, professor do Departamento de Educação Física da Universidade Federal de Minas Gerais, Belo Horizonte, MG - Brasil, e-mail: marcustaborda@uol.com.br 


\section{Resumo}

Este texto é parte da pesquisa concluída que explora alguns dos pressupostos da puericultura como prescrição curricular para a Escola Maternal da Sociedade de Socorro aos Necessitados (SSN), criada em Curitiba em 1928. Entre tantas atividades previstas pelos idealizadores daquela instituição de assistência à infância, a Escola Maternal se caracterizou pela preocupação em oferecer a escolarização à infância ali assistida, cobrindo as idades de 0 a 12 anos, em três fases distintas: a creche, o jardim de infância e o curso doméstico. Nela a puericultura, a moral e o trabalho ganhavam relevo, e apresentavam-se como eixos de fundamental importância para a concretização do "objetivo máximo da Escola Maternal: higiene, ordem e disciplina". Entendidas essas três dimensões da formação como intrinsecamente ligadas à educação do corpo e das sensibilidades, consideramos que o espargir da puericultura, da moral e do trabalho foi realizado com base na desqualificação da maior parte da população não só local, mas brasileira, ainda carente de um "choque de civilidade". Na documentação captamos ecos de um momento fundador do currículo, a sua prescrição, verificando como a puericultura se articulava à moral na tentativa de desenvolver uma sensibilidade afeita ao mundo do trabalho. Este, por sua vez, era justificado por uma retórica de cunho religioso, assistencial e caritativo para afirmar em corações e mentes infantis o lugar de cada um naquele mundo.

Palavras-chave: Educação da infância. História do currículo. Puericultura.

\section{Abstract}

This work is the result of a research that explores some assumptions of childcare as a curriculum prescription for the Maternal School of the Sociedade de Socorro aos Necessitados (SSN), created in Curitiba, in 1928. Among all the activities provided by the creators of that child care institution, the Maternal School characterized by the concern to provide schooling to childhood there assisted, covering the ages of 0 to 12 years in three different phases: creche, the kinder garden and the home studies. In this institution, childcare and labour earned relief, though under other names they were also present in the previous actions of SSN. Understood these three dimensions of formation as intrinsically linked to the education of the body and sensitivities, we consider the scatter of childcare, moral and labour was based on the disqualification of most of the population not only local, but all 
around Brazil, that still lacks a "clash of civility". This should internalize the rules taught to them, for the training on sanitized, educated and moralized individuals, under the epithet of "citizens", regardless of the material conditions that determine their condition of poverty and abandonment. Based on the sources analyzed, it is observed that under the perspective adopted by the childcare in the actions of the Maternal School were based on scientific principles scattered mostly in Congress, among other places of great circulation of ideas. These ideas, in turn, made up the proposals from other institutions and based the speeches of doctors, lawyers, politicians, journalists, among many other professionals who considered these principles as fundamental in the education of the population. Thus, it is mobilized documents of varied nature, such as those emanated from inside the SSN (minutes, correspondence, reports and programs), plus the daily press and the production of intellectuals linked to the causes of education and poor child care. In the documentation we catch echoes of a founding moment of the curriculum, its prescription, noting how the childcare was linked to moral in an attempt to develop a sensitivity accustomed to the world of work. This world, in turn, was justified by rhetoric of a religious, caring and charitable nature to affirm in the children's hearts and minds the place of every one in that world.

Keywords: Childhood education. History of the curriculum. Childcare.

\section{Introdução}

Em O mal-estar na civilização, Freud (1997) diagnosticava que as chamadas sociedades modernas estavam alicerçadas sobre a tríade higiene, ordem e beleza. Para o autor, um dos dilemas da civilização era justamente dimensionar o preço a pagar pelo desenvolvimento de uma determinada sensibilidade - moderna, a qual teria se definido lentamente desde o século XIX em torno do chamado mundo do trabalho, para os pobres (GAY, 2001), e da expansão dos tempos livres do trabalho, para as cada vez mais vicejantes camadas médias (HOBSBAWM, 1996), em diferentes lugares do mundo.

$\mathrm{Na}$ mesma década em que o pensador austríaco tecia com rara lucidez sua crítica à cultura moderna e hiperdesenvolvida do capitalismo 
industrial, no Paraná se conhecia um significativo debate justamente sobre algumas daquelas premissas sugeridas por Freud. Daquele debate nasceria, entre outras iniciativas, a Sociedade de Socorro aos Necessitados $\left(\mathrm{SSN}^{1}\right)$, a qual fundaria, em 1928, uma escola maternal. A Escola Maternal da Sociedade de Socorro aos Necessitados ${ }^{2}$ fundamentava o seu trabalho na moral, na puericultura e no trabalho (TURINA, 2010), caracterizando uma clara disposição de agir sobre corpos e mentes dos seus pequenos frequentadores. Segundo os seus regulamentos, aqueles três preceitos apresentavam-se como eixos de fundamental importância para a concretização do "objetivo máximo da Escola Maternal: higiene, ordem e disciplina” (Sociedade de Socorro aos Necessitados, 13 abr. 1929).

Entre tantas atividades previstas pelos idealizadores daquela instituição, a Escola Maternal se caracterizou pela preocupação em oferecer escolarização à infância ali assistida, cobrindo as idades de 0 a 12 anos, em três fases distintas: a creche, o jardim de infância o curso doméstico, este apenas para meninas. Naquela estrutura, consideramos que o espargir da puericultura, da moral e do trabalho foi realizado com base na desqualificação da maior parte da população não só local, mas brasileira, ainda "carente" de um choque de civilidade. Esta deveria internalizar as normas que lhes eram ensinadas, visando à formação de indivíduos higienizados, civilizados e moralizados, sob o epíteto de "cidadãos", independente das condições materiais que determinavam sua condição de pobreza e abandono.

Se considerarmos, ainda, que as sensibilidades consideradas modernas estavam ancoradas em novas formas de educação do corpo e dos sentidos da infância pobre - mas nem sempre abandonada - então entendemos que se faz necessário compreender o papel conferido

1 A Sociedade de Socorro aos Necessitados foi fundada em 1921 na cidade de Curitiba e sua principal ação foi o recolhimento de mendigos e necessitados em casas alugadas e vilas criadas para esse fim. Atualmente, as atividades da SSN direcionam-se ao atendimento de idosos e crianças, tendo a instituição um asilo e uma creche como suas principais ações.

${ }^{2}$ As discussões iniciais que provocaram a escrita deste texto foram apresentadas na dissertação intitulada Escola maternal: história, assistência e escolarização da infância em Curitiba (19281944), Turina, 2010. 
à puericultura naquele tempo e lugar. Nosso objetivo é, pois, explorar neste trabalho alguns dos pressupostos da puericultura como prescrição curricular naquela instituição educativa. É possível afirmar, com base nas fontes analisadas, que a perspectiva de puericultura, moral e trabalho adotada nas ações da Escola Maternal e da Sociedade de Socorro aos Necessitados estava embasada em preceitos científicos difundidos principalmente em congressos, entre outros espaços de grande circulação de ideias. Esses preceitos, por sua vez, não estavam restritos ao âmbito daquela instituição, mas compunham as propostas de outras instituições e embasavam os discursos de médicos, juristas, políticos, jornalistas, entre tantos outros profissionais que consideravam esses princípios como fundamentais na educação da população.

Para tanto, mobilizamos documentação de natureza variada, como aquela emanada do interior da Sociedade de Socorro aos Necessitados (atas, correspondência, relatórios, programas, etc.); da Escola Maternal, além da imprensa diária e da produção de intelectuais ligados às causas da educação e da assistência à infância pobre, para indagar no âmbito prescritivo o que se formulou para a educação da infância pobre em Curitiba na década de 1920. Tomando a prescrição como um momento fundador do currículo (GOODSON, 1995) e observando o quanto esse artefato social agiu sobre a educação dos corpos e das sensibilidades (TABORDA DE OLIVEIRA, 2006), procuramos verificar como a puericultura se articulava à moral e ao trabalho na tentativa de desenvolver uma sensibilidade afeita ao mundo "moderno", de forte assento laboral. Esse assento, por sua vez, era justificado por uma retórica de cunho religioso, assistencial e caritativo, para afirmar em corações e mentes infantis - pobres - o lugar de cada um no novo mundo de acelerado progresso.

\section{Preceitos de puericultura e a nova sensibilidade do trabalho}

É necessário compreender os princípios da puericultura e o lugar que ocupavam nos debates educacionais para problematizar sua relação 
com os objetivos e as ações da Escola Maternal. Segundo Rocha (1987), a puericultura surgiu na França no fim do século XVIII e foi definida como o conjunto de normas sobre a arte de criar fisiológica e higienicamente as crianças. O seu desenvolvimento permitiu a sua consolidação em estreita relação com a área da saúde. Refere-se aos cuidados preventivos com a fisiologia, a higiene, a nutrição, entre outros elementos que favoreçam o bom desenvolvimento físico, psicológico e social de crianças, desde a gestação até a puberdade. Essas noções abrangem desde normas de ordem médica, nutricional, psicológica, de higiene, como também aspectos sociais, afetivos, etc. Rocha (1990) lembra que a puericultura passou por certo aperfeiçoamento desde seu surgimento e que nos dias atuais tem como objetivo formar um "adulto perfeito", fisicamente sadio, psiquicamente equilibrado e socialmente útil. Logo, ela era e é muito mais que uma rubrica no currículo escolar, ainda que esteja presente na formação de professoras, por exemplo, desde o séc. XIX (VILLELA, 2002). Além disso, o seu desenvolvimento e as mudanças que sofreu parecem em estreita relação com as mudanças ocorridas no âmbito dos saberes médicos.

Percebe-se que no período analisado a puericultura se configurou dessa mesma forma, como um conjunto de normas e condutas direcionadas ao trato da infância, com forte apelo cientificista (TURINA, 2010). Martagão Gesteira ([1943] 1996, p. 72), ao realizar um breve histórico sobre a puericultura, destacou que

o interesse e o cuidado pelos meninos se foram tornando cada vez maiores e desdobrando-se em medidas legislativas de amparo à mãe e à criança, em obras diversas de assistência moral, material, médica e jurídica à maternidade e à infância desvalida, tudo o que constitui hoje o acervo duma verdadeira ciência, extremamente vasta e complexa, a que se ajusta bem o termo puericultura [...].

A definição estaria feita não fosse a perspectiva que se considera, neste trabalho, que existiam duas concepções distintas para o termo puericultura. Conforme Bonilha e Rivorêdo (2005, p. 7), uma delas baseava-se no pressuposto de pensar os cuidados à criança "em todos os 
aspectos biológicos, psicológicos e sociais", como vimos antes, de modo que se pudesse "prevenir doenças e auxiliar na expressão genética plena", visando à melhor formação do adulto. Segundo Bonilha e Rivorêdo (2005, p. 8), essa perspectiva, apresentava-se com "caráter neutro e positivo" e desconsiderava outra concepção que apresentava "a puericultura como uma prática social sujeita aos mais diversos agentes políticos e econômicos, com motivos, objetivos e consequências que extrapolam a simples elaboração de normas científicas que assegurem o desenvolvimento da criança" (BONILHA; RIVORÊDO, 2005, p. 8). Essa segunda acepção sustenta as discussões realizadas neste trabalho, o qual entende existir "encobertos sob a proposta de prevenir a mortalidade infantil por meio da educação, outros projetos, como o do estabelecimento de um padrão de comportamento não só para as crianças, mas para as famílias como um todo, de cunho moralizante e baseado naquele considerado ideal pelas classes dominantes" (BONILHA; RIVORÊDO, 2005, p. 8).

Assim, arriscamos afirmar que a puericultura contribui para a educação da sensibilidade, na medida em que ajuda a definir padrões de comportamentos acordes com determinados interesses ou finalidades, sejam políticos, culturais, econômicos, ou morais, seja como um saber médico-científico, seja como uma disciplina escolar. Não por acaso ela esteve presente no currículo escolar, tanto ao nível das Escolas Normais quanto da instrução primária (PYKOSZ, 2007). Desse modo, na segunda acepção, os seus preceitos científicos se modificariam de tempos em tempos, e ela manteria apenas seu princípio ideológico de manutenção da ordem social imposta por meio da educação e da assistência das novas gerações. Além de cuidados higiênicos, médicos ou legislativos, entre outros, a puericultura envolveria também uma perspectiva de incutir na criança e na família determinados padrões de comportamento moral.

A difusão da puericultura no Brasil ocorreu de forma intensa no fim do século XIX e início do XX, e se baseou em normas já difundidas em outros países. Ao se referir ao problema das altas taxas de mortalidade infantil averiguadas no Brasil, Arthur Moncorvo Filho destacava que "procurávamos estudar o problema tanto quanto permitiam as nossas forças e 
apreender as noções do que de profícuo se fazia em todas as nações cultas em bem da criança" (MONCORVO FILHO, 1927, p. 127).

O estudo do problema ao qual se refere Moncorvo Filho conferia à medicina status de saber legitimado, no qual as consequências da não efetivação daquelas orientações causariam danos à criança e, consequentemente, à sociedade. Desse modo, valendo-se das descobertas e retóricas científicas, os médicos associavam a falta de higiene e os cuidados com o corpo a outros aspectos considerados nocivos à formação da criança, como a carência de conduta moral e intelectual das pessoas. $\mathrm{O}$ abandono moral, a ignorância e o analfabetismo, somados à falta de higiene, colocariam em risco o objetivo de formar o cidadão saudável, robusto e útil à sociedade. O combate às mazelas citadas, associadas à falta de higiene e de cuidados com o corpo infantil, se configurava como noção de puericultura que deveria ser transmitida às mães e também às professoras. Essa retórica fundava boa parte dos discursos renovadores no âmbito educacional, no Brasil, na década de 1920. Não por acaso, na I Conferência Nacional de Educação, realizada em Curitiba em 1927, parte significativa das teses discorria sobre as diferentes formas de educação do corpo.

Assim, naquela ambiência de renovação educacional, de cruzada pela "salvação" da infância, tal como para Moncorvo Filho, a professora paranaense Annette Macedo também defendia a necessidade de "conhecer e aplicar os preceitos fundamentais da puericultura, saber cultivar crianças, para que sejam sadias e robustas" (MACEDO, 1928b, p. 135). A professora, que seria diretora da Escola Maternal e autora dos seus programas de ensino, corroborava o discurso que circulava no período em relação à necessidade de amplos cuidados com as crianças pequenas.

Em um período em que diferentes doutrinas eugênicas davam o tom de muitos discursos renovadores, os princípios de puericultura defendidos por alguns intelectuais pautavam-se nos discursos médicos-científicos de melhoria da raça. Conforme destacava Moncorvo Filho (1927, p. 139), o objetivo daquela verdadeira "cruzada" era

introduzir em nosso meio quanto de profícuo fosse sendo (sic) adotado nos mais adiantados países, agindo em todos os sentidos e 
particularmente estabelecendo uma enérgica e extensa propaganda de higiene infantil, ensinando-se ao povo a verdadeira puericultura, para que pudesse o Brasil alcançar, ao cabo de algum tempo, o ideal dos povos civilizados - o melhoramento e a robustez de sua raça pela aplicação utilíssima das regras da Eugenia.

Na perspectiva do autor, seguidas na Escola Materna de Curitiba, as regras de eugenia auxiliariam a formação do cidadão sadio, moral e útil à pátria, atuando como uma medida de adaptação social dos sujeitos ditos "desajustados". Os apontamentos do médico carioca não eram alusivos às ideias da eugenia referentes ao branqueamento, como em outros registros; mas sim, ao uso da ciência como instrumento de aprimoramento e salvação da população pobre, e como possibilidade de destituir a ignorância e os hábitos de vida insalubres daquela. Isso porque, segundo grande parte dos intelectuais do período, a ignorância e os maus hábitos eram os responsáveis pela disseminação de doenças e degeneração da população, tal como já postulava Fernando de Azevedo ([1916] 1961).

Assim, consideramos que a puericultura apresentava-se como um conjunto de regras com orientação eugênica para a primeira infância, pois a busca pelo tipo ideal de cidadão sadio, bem formado social e psiquicamente começava com os cuidados pré-natais e infantis. Ou, ainda, pode-se afirmar que, no período analisado, a puericultura se conformou aos moldes do modelo eugênico de cidadão e ajudaria a reforçar os discursos higienistas disseminados no Brasil desde o século XIX. Desse modo, é possível ponderar que servia à disseminação dos preceitos eugênicos e higiênicos de cunho moralizante, como ferramenta de prevenção aos maus comportamentos da população pobre. Com base nessas considerações, entende-se que as normas de puericultura mencionadas no regimento da Escola Maternal coincidiam com as orientações referentes aos cuidados higiênicos, físicos e morais com as crianças pequenas atendidas naquela instituição.

A prática de realizar palestras educativas na Escola Maternal, direcionadas às mães das crianças matriculadas, expressa o lugar que a instituição pretendia ocupar na vida familiar. Ditar "conselhos úteis e 
bem explicados sobre a moral e decoro no lar, preceitos sobre a higiene do corpo, ordem e asseio" (ESCOLA MATERNAL DA SOCIEDADE DE SOCORRO AOS NECESSITADOS, 1930, p. 3) era o foco da instituição, sob a argumentação de que assim as famílias poderiam contribuir com a obra da Escola Maternal. Certamente essa prática implicava desqualificar a família como instituição apta a tratar da formação das crianças. A difusão da puericultura na Escola Maternal pretendeu não só orientar hábitos de higiene, mas também regular a vida íntima das famílias, ajustando ações tanto internas quanto externas a casa e à família, enfim, à vida privada (BOLTANSKI, 1972). Aquelas ações sempre estavam balizadas pela prescrição de condutas civilizatórias aliadas à apologia do trabalho.

A proposta de atendimento às crianças da creche se baseava nas noções de puericultura que circulavam no período e referiam-se aos cuidados da higiene do corpo, da alimentação da criança, seu estado de saúde, entre outras questões. Um breve relato de Moncorvo Filho, cuja obra funcionava como um verdadeiro guia didático, permite observar quais outros elementos poderiam estar a cargo da puericultura:

a) Proteção à mulher grávida; b) Berços - Seu histórico desde a antiguidade - Leitos adotados e leitos condenados pela higiene; c) Mamadeiras, bicos e chupetas - Classificação das mamadeiras - tipos perigosos e condenados; d) Alimentação da primeira infância Aleitamento natural (materno e mercenário), misto e artificial; aparelhos de esterilização de leite (modelos), leites industriais, farinhas alimentícias; estatísticas sobre os diferentes regimes adotados na alimentação da primeira idade, radiografia do estomago da criança, digestão dos alimentos, fezes normais e patológicas [...]; e) Alimentação da segunda infância; f) Vestimenta - Tipos de envoltórios: roupas prejudiciais, tipos de roupas higiênicas que devem ser adotadas de acordo com os climas; g) Amuletos e abusões; h) Concursos de Robustez; i) Dentição (MONCORVO FILHO, 1927, p. 375-376).

Muitos dos elementos apresentados pelo autor referem-se a objetos de uso cotidiano da criança pequena. Aqueles seriam indicados ou contraindicados de acordo com pressupostos estranhos às famílias, o que 
requeria uma intervenção educativa sobre crianças e famílias. Vale reiterar que aquela intervenção na forma de prescrições sobre o que deveria ou não ser utilizado no trato das crianças, desencadearia um conjunto de consequências no qual cada vez mais as famílias seriam desobrigadas de avaliar e decidir o que poderia ser bom ou não aos seus filhos. Do mesmo modo que se pode flagrar o processo de desqualificação da família pela escola, com o espraiamento da escola de massas (CUNHA, 2003), aqui o processo de desqualificação da experiência familiar estava a cargo da puericultura e dos saberes médicos. A escola se apresentava como o espaço por excelência de conhecimento legítimo e, em estreita parceria com os médicos, pretendia fazer chegar a boa parte dos lares os preceitos higiênicos considerados adequados à ambiência urbana.

Entretanto, os preceitos da puericultura não estavam presentes apenas nas ações da creche, mas também em outra modalidade da Escola Maternal, o curso doméstico. No regimento da Escola Maternal consta que no curso doméstico, destinado a formar "boas mães de família", as alunas receberiam "conhecimentos práticos de Puericultura" (ESCOLA..., 1928, p. 121). Não há menção no regimento a uma disciplina específica para o ensino da puericultura, porém os artigos do documento permitem observar que os saberes afeitos a ela deveriam ser difundidos em vários momentos, pois o "Curso Doméstico ministrará às meninas de mais de 7 anos a cultura física, intelectual, afetiva, ativa, moral, cívica e estética necessárias às boas mães de família" (ESCOLA..., 1928, p. 119). Outros aspectos relacionados à puericultura também estavam presentes no item do regimento sobre o curso doméstico, como higiene, ginástica, cuidados com o corpo, direitos e deveres entre marido e mulher e cultura cívica e patriótica.

A partir daquele programa que mesclava uma dimensão enciclopédica com um caráter claramente utilitário, podemos considerar que a puericultura se configurou de duas formas distintas na Escola Maternal: como proposta de formação, no sentido lato; e como proposta de escolarização. Na atuação da creche, o objetivo das ações baseadas na puericultura era formar indivíduos adequados às normas de higiene e conduta moral 
desde pequenos, educando-os, a partir das prescrições da medicina científica, na direção da eficiência social (HAMILTON, 2001), segundo esperavam os grupos dominantes. Em um momento onde pululavam as greves operárias, grassavam ainda as epidemias, transbordava a miséria e a mendicância, esperava-se antecipar a ocupação do espaço urbano evitando problemas futuros para a sociedade curitibana. Ali, cuidar das crianças significava educá-las e moldá-las de acordo com uma nova sensibilidade, o que nos faz concordar com a tese defendida de Kuhlmann Jr. (2004), para quem, no cuidar e no assistir, também está inscrita uma proposta educativa.

As orientações apresentadas no Regimento e nos relatórios da Escola Maternal permitem afirmar que não se tratava de uma proposta de educação emancipatória ou transformadora, que recuperasse a utopia do esclarecimento, mas uma educação de caráter preventivo, desenvolvida como forma de evitar os males sociais que supostamente a pobreza carregava consigo. Desse modo, entendia-se que o problema estava no outro, no indivíduo pobre e na sua família, que traziam consigo doenças, maus hábitos e desvios de todo tipo, como que de forma hereditária.

$\mathrm{Na}$ perspectiva do curso doméstico o destaque estava no processo pelo qual a ciência da pediatria vulgarizou parte de seus conhecimentos transpondo algumas normas de puericultura para a escola, algo como uma disciplina curricular, processo esse que se pode denominar escolarização dos saberes da puericultura. É importante destacar que essa perspectiva de escolarização foi marcada pela proposta de tornar algo não escolar adaptado para o espaço escolar, com a finalidade de novamente disseminar esses saberes para o ambiente extraescolar, nesse caso o ambiente familiar, denotando algumas das múltiplas finalidades identificadas por Chervel (1990) na constituição de uma disciplina escolar. Tratavase de ensinar parte dos saberes médicos relacionados à puericultura com a finalidade de garantir a manutenção da ordem e civilidade, pela via da saúde e da moral. No que se refere à associação entre médicos e educadores, Annette Macedo, por exemplo, defendia que estes eram responsáveis por duas missões distintas na sociedade, porém que não se dissociam: a da pediatria e a da pedagogia. 
Não obstante, a pobreza era identificada como a grande causadora dos problemas da sociedade civilizada. O entrave do desenvolvimento social e econômico estava associado à perspectiva do pobre como agente âncora, aquele que atrasava ou, ainda, que destruía as possibilidades de modernização da cidade e da sociedade, representação que calaria fundo nos discursos das elites brasileiras desde então. Para os defensores do discurso da modernização, a prevenção apresentava-se como a melhor ou única forma de garantir que os germes da pobreza se dissipassem pela urbe. Ser pobre, nascer pobre, implicava carregar consigo as chagas biológicas e sociais indesejadas na vida da sociedade em modernização. Por esses motivos, as normas de puericultura difundidas entre a população, seja pela escola ou por outros espaços, não se restringiram a hábitos de higiene, de alimentação, de vestimenta, mas também aos modos de convivência social e moralização do sujeito pobre, para que ele pudesse "ocupar seu lugar" na cidade, de forma considerada adequada. Daí depreendermos que as prescrições da puericultura podem ser consideradas como um dos elementos moralizadores mais vigorosos no processo de educar e escolarizar a infância pobre e a sua família no início do século XX em Curitiba.

Nessa direção, a retórica do trabalho se constituiu, nos discursos das elites sobre o sujeito pobre, como um dos principais elementos de adequação às novas sensibilidades. Moral e trabalho se apresentavam de forma associada e guardavam grande relação com a puericultura. A moralização dos sujeitos pelo trabalho era um discurso recorrente no fim do século XIX e início do século XX. Segundo Karvat (1998, p. 30), o “apego ao trabalho implicava no alargamento dos atributos morais. Quanto mais dedicado e abnegado o indivíduo fosse ao trabalho, tanto mais moralizado seria". Com base nessa argumentação buscava-se construir uma imagem positiva do trabalho na vida dos indivíduos - ainda que, como mostra Hobsbawm (1996), a apologia do trabalho era destinada apenas àquelas classes que podiam se dedicar ao ócio. O sujeito desinteressado pelo trabalho era considerado como desprovido de valores morais e, como consequência, uma ameaça à ordem e à paz social. Aqueles indivíduos necessitavam de uma educação moral que inculcasse valores contra a ociosidade e o desapego ao trabalho. 
O discurso sobre a importância do trabalho como aspecto moralizador da vida dos cidadãos pautava-se na argumentação do ócio e da vadiagem como causas da criminalidade. Os sujeitos sem ocupação eram considerados como os mais propensos a cometer atos ilícitos, fossem crimes ou outros distúrbios à ordem, como, por exemplo, farras em bailes, bebedeiras, mendicância, entre outros, como bem demonstra De Boni (1985). A condição social de cada um não era dada por uma sociedade baseada no favor, no beneplácito, no poder político ou econômico. Trabalho, higiene e moral pareciam ser "naturalmente" constitutivos das elites, e faltariam aos mais pobres. Daí a necessária assepsia da cidade, para a qual contribuiria a educação. Para a vadiagem haveria solução: inculcar novos valores morais nos pobres e direcioná-los para o trabalho produtivo, para a conduta ordeira e a higiene desejada. Fazia-se necessária constante vigilância e a manutenção da ética do trabalho na vida da população pobre, pois se esta perdesse a condição de trabalhadora, a ociosidade e a propensão ao crime permaneceriam como um fato da sua "natureza". Não é demais, pelas fontes que dispusemos, afirmar que a educação da sensibilidade trata, mesmo, da construção de uma segunda natureza no homem. Nesse caso, pautado pelo trabalho, pela eficiência social e pelo apego à ordem e à saúde. Daí que os pobres seriam portadores de duas situações distintas, estar ou não estar trabalhando, e de apenas uma condição "natural”, ser pobre, o que implicava ser predisposto a maus hábitos de conduta moral e higiênica (TURINA, 2010).

A Sociedade de Socorro aos Necessitados foi fundada em 1921 com o objetivo de recolher os vadios que perambulavam pelas ruas da capital paranaense. Em 1928, após alguns anos atuando no recolhimento de mendigos e necessitados, a Sociedade de Socorro organizou a Escola Maternal sob o pretexto de "proteger a criança, desde o berço, até a sua primeira educação" (NERY, 1928, p. 148). A intenção era proteger a criança de sua própria origem, da pobreza de sua família, da falta de higiene e de moral, em uma perspectiva que se pode dizer de correção e não de prevenção. Era preciso "combater os germes do mal, cultivar os do bem, a fim de preponderarem 
estes eficazmente, sem contraste, como base do caráter" (MACEDO, 1928b, p. 130). A Escola Maternal, que segundo seus proponentes destinava-se à prevenção, na verdade apresentava-se como uma proposta de correção, pois condenava a origem social das crianças. Como os "germes do mal", fossem eles a vadiagem, a imoralidade e a falta de higiene, eram elementos constituintes do caráter do pobre, sendo de origem hereditária, era necessário corrigir o caráter da criança pobre o quanto antes.

A moral, conforme discurso da época, era o elemento base de formação do caráter do indivíduo, e assim as ações do jardim de infância foram organizadas para "estimular e consolidar as boas tendências e os hábitos bons” (ESCOLA..., 1928, p. 119). No jardim de infância da Escola Maternal, as crianças deveriam ter autocontrole, estimulando a "vontade inibitória das tendências más" e assim "cultivar bons hábitos" (Escola Maternal da Sociedade de Socorro aos Necessitados, 1928, p. 119). A moral se assemelharia ao solo onde seriam plantadas as sementes da higiene e do trabalho, para as quais, como vimos, a puericultura contava um papel crucial. Ser um sujeito de hábitos de higiene e trabalhador significava possuir uma boa moral e estar apto para contribuir com o engrandecimento da nação. Para desenvolver a "boa moral", Moncorvo Filho (1927, p. 146) defendia que era necessário "desenvolver os sentimentos da honra e da virtude" e para atingir tal objetivo era necessário recorrer à "inteligência e sobretudo ao coração, quer dizer, moralizar o cidadão".

Nas ações do jardim de infância da Escola Maternal também se entendia que era necessário avaliar "o grau de atividade mental de cada criança, a fim de as classificar (sic) em grupos homogêneos", em um processo que visava a conhecer "as tendências ou inclinações de cada criança" no que se refere à moral (Escola..., 1928, p. 118).

A proposta para o jardim de infância era

dirigir todos os exercícios e diversões, de modo que, em seus atos, as crianças adquiram hábitos de polidez, de modéstia verdadeira, de bondade, de justiça, de sinceridade, de dignidade, de discrição, de 
moderação, de prudência, de coragem e de ordem e, em suma, de cumprimento de seus deveres (Escola..., 1928, p. 119).

Todo o tempo e todas as atividades das crianças eram controlados e tinham objetivos educativos. A exemplo do que ocorria com a transmissão das normas de puericultura, a escola novamente ocupava o lugar principal de difusão dos preceitos morais socialmente valorizados. Também ali a família era considerada como desprovida de condições higiênicas e morais para educar os filhos; desse modo a escola assumia a educação das crianças pobres. O objetivo não era restabelecer a família como locus principal de educação das crianças, e sim educá-la por meio das crianças. Conforme mencionou Annette Macedo (1928b, p. 131), ao pretender "proteger" a criança de suas próprias origens

protege-se também, indiretamente, sua pobre mãe, seja esta uma empregada doméstica, uma operária ou uma libertina. E, se libertina, essa mãe é duplamente infeliz, e por isso mesmo sua filhinha ou seu filhinho mais necessita dos nossos cuidados, que nela poderão refletir-se para que mude de rumo.

Os valores morais que seriam adquiridos no jardim de infância tinham como finalidade 'preparar' as crianças para receberem a formação para o trabalho. A própria ideia de elevação moral das crianças tinha na importância conferida ao trabalho um elemento formador do bom caráter por excelência. Annette Macedo (1934, p. 65) argumentava que "o trabalho é uma necessidade, é uma benção de Deus. As crianças trabalhando se educam". No caso da Escola Maternal, os meninos permaneciam na instituição somente até a conclusão do jardim de infância, departamento intermediário. Depois, eram encaminhados a outras instituições, na maioria dos casos escolas profissionais ou de ofícios destinadas às crianças desvalidas e/ou abandonadas. Já as meninas permaneciam na Escola Maternal para frequentarem o curso doméstico, que seria o equivalente do curso primário, porém, como vimos, acrescido de outros objetivos: moldar as meninas para se tornarem "boas mães". Dentro da perspectiva 
almejada pelos organizadores da Escola Maternal, isso significava ter uma formação voltada para as noções de puericultura e moral, mas destinadas ao mundo do trabalho.

Ao chegar à idade de frequentar o curso doméstico, as meninas eram iniciadas no mundo do trabalho de forma prática, pois, de acordo com o art. 25 do regimento da Escola Maternal, "por determinação da Diretora serão as meninas, em horas propícias, empregadas em serviços da Creche, compatíveis com a sua idade e constituição física, como meios de educação doméstica, dando-se lhe então conhecimentos práticos de Puericultura" (Escola..., 1928, p. 121).

É possível afirmar que esse artigo do regimento visava a, no mínimo, quatro propósitos complementares entre si: a valorização do trabalho na vida das meninas; o uso da mão de obra das meninas de duas formas diferentes na instituição; a formação de mão de obra qualificada para o trabalho doméstico em casas "de família"; e, principalmente, a moralização e o enquadramento daquelas que seriam as futuras mães pobres. O curso doméstico dava continuidade ao processo de moralização das meninas iniciado na creche. A valorização do trabalho ganhava destaque com a execução de tarefas pelas garotas, que desde muito pequenas eram incentivadas ao trabalho produtivo. Era chegada a hora de colocar em prática as noções de puericultura e os princípios morais aprendidos ao longo dos anos de creche e de jardim de infância.

A conclusão do curso doméstico conferia às meninas formação para o trabalho doméstico. Como se tratava de uma clientela pobre essa era uma alternativa, de certa forma garantida, de colocação profissional que reduzia as chances das meninas ficarem perambulando pelas ruas da cidade, e/ou praticando a mendicância. Ao mesmo tempo, o curso doméstico proporcionava às famílias com posses a oportunidade de contratar empregadas domésticas com certa experiência no trato diário com crianças, com conhecimentos técnicos sobre atividades domésticas adquiridos em uma instituição escolar, assumindo um caráter utilitário.

A importância do trabalho é o que predomina nos artigos sobre o curso doméstico, no entanto, no seu Regimento consta que a finalidade máxima desse departamento da E.M. era formar "boas mães" de modo que: 
tudo na Escola tem de visar esse fim; e especialmente:

1. ${ }^{\circ}$ - os trabalhos manuais de utilidade doméstica, inclusive horticultura e floricultura;

2. ${ }^{\circ}$ - as noções

a) - de contabilidade doméstica;

b) - de economia doméstica;

c) - de higiene e de medicina caseira (Escola Maternal da Sociedade de Socorro aos Necessitados, 1928, p. 120).

Uma vez mais vemos articulados os preceitos da puericultura e a tônica da moralização aliados ao preparo para o trabalho. O caráter daquelas trabalhadoras deveria ser comedido, higiênico e ordeiro. As meninas recebiam orientações para que, quando fossem mães, atuassem em seus lares conforme as normas recebidas nos anos de formação do curso doméstico, alterando as práticas familiares até então transmitidas de geração para geração. O objetivo era conformar novos hábitos de conduta novas sensibilidades - nas meninas e, consequentemente, em suas futuras famílias, na perspectiva que a família seria a menor célula da sociedade e refletiria a postura "moralizada" dos seus membros na cidade e na nação que se modernizavam.

No regimento da Escola Maternal consta que:

Art. $21^{\circ}$ - Tudo na Escola será elemento de cultura moral, completada por noções singelas e práticas, concernentes:

a) - aos deveres relativos a nós mesmos, aos nossos semelhantes, à Família, à Escola e à Pátria;

b) - à felicidade de ser bom e justo, à satisfação da consciência, fonte da alegria de viver;

c) - às necessidades primordiais da vida humana; aos direitos e deveres relativos a cada uma;

d) - ao casamento, base da família;

e) - aos direitos e deveres entre marido e mulher; e

f) - à bondade e à justiça de Deus, base de todas as religiões (Escola Maternal da Sociedade de Socorro aos Necessitados, 1928, p. 120). 
As meninas deveriam compreender que delas dependia a modernização e o progresso da nação. Pretendia-se que as alunas compreendessem o lugar de importância da família, da Igreja, da escola e do Estado em suas vidas, demonstrando que de todas essas instituições sociais a mais vulnerável e que necessitava de maior orientação era a família. Todo o cotidiano da família e dos cuidados com os filhos passou a ser regulado e regrado de acordo com normas de conduta, de higiene, de respeito e de comedimento. Formando novos hábitos nas alunas, estas constituiriam suas famílias sob uma nova perspectiva de indivíduo, ordeiro e trabalhador. Educar aquela nova sensibilidade pela higiene, pela moral e pelo trabalho tratava-se, pois, de uma reforma da família pobre e era um forte testemunho das bases sobre as quais se constituiu a modernidade na sociedade brasileira, sendo as prescrições da puericultura uma chave para o entendimento daquele contexto.

\section{Referências}

AZEVEDO, F. de. A poesia de corpo. Rio de Janeiro: Weiszflog, ([1916] 1961).

BOLTANSKI, L. Puericultura e morale di classe. Tradução Cesare Marconi. Firenze: Guaraldi, 1972.

BONILHA, L. R.; RIVORÊDO, C. R. Puericultura: duas concepções distintas. Jornal de Pediatria, Rio de Janeiro, n. 81, p. 7-13, 2005.

CHERVEL, A. História das disciplinas escolares: reflexões sobre um campo de pesquisa. Teoria e Educação, Porto Alegre, n. 2, p. 177-229, 1990.

CUNHA, M. V. A escola contra a família. In: LOPES, E. M. T.; FARIA FILHO, L. M.; VEIGA, C. G. 500 anos de educação no Brasil. 3. ed. Belo Horizonte: Autêntica, 2003. p. 447-468.

DE BONI, M. I. M. 0 espetáculo visto do alto: vigilância e punição em Curitiba (1890-1920). 1985. Tese (Doutorado em História Social) - Universidade de São Paulo, São Paulo, 1985. 
ESCOLA MATERNAL DA SOCIEDADE DE SOCORRO AOS NECESSITADOS. Regimento da Escola Maternal de Socorro aos Necessitados, 1928. In: MACEDO, F. R. A. Felicidade pela educação: ensaios pedagógicos da professora Annette Clotilde Macedo. Curitiba: Gerpa, 1952. p. 116-125.

ESCOLA MATERNAL DA SOCIEDADE DE SOCORRO AOS NECESSITADOS. Relatório oficial apresentado ao Conselho deliberativo da Sociedade de Socorro aos Necessitados. Anos: 1930, 1932, 1935, 1939.

FREUD, S. O mal-estar na civilização. Rio de Janeiro: Imago, 1997.

GAY, P. Guerras do prazer: a experiência burguesa da Rainha Vitória a Freud. São Paulo: Companhia das Letras, 2001. v. 5.

GOODSON, I. F. Currículo: teoria e história. Petrópolis: Vozes, 1995.

HAMILTON, D. Notas de lugar nenhum: sobre os primórdios da escolarização moderna. Revista Brasileira de História da Educação, n. 1, p. 45-73, jan./ jun. 2001.

HOBSBAWM, E. J. A era dos impérios. Rio de Janeiro: Paz e Terra, 1996.

KARVAT, E. C. A sociedade do trabalho: discursos e práticas de controle sobre a mendicidade e a vadiagem em Curitiba, 1890-1933. Curitiba: Aos Quatro Ventos, 1998.

KUHLMANN Jr., M. Infância e educação infantil: uma abordagem histórica. 3. ed. Porto Alegre: Mediação, 2004.

MACEDO, A. C. P. Conferência Pedagógica na Associação Paranaense de Educação, 1928a. In: MACEDO, F. R. A. Felicidade pela educação: ensaios pedagógicos da Professora Annette Clotilde Macedo. Curitiba: Gerpa, 1952. p. 127-134.

MACEDO, A. C. P. Educação Doméstica (Tese apresentada à Conferência Pedagógica de Belo Horizonte), 1928b. In: MACEDO, F. R. A. Felicidade pela educação: ensaios pedagógicos da Professora Annette Clotilde Macedo. Curitiba: Gerpa, 1952. p. 135-137. 
MACEDO, A. C. P. Prova escrita do concurso. Ponto sorteado: adaptação da escola ao ambiente regional. 3 set. 1934. In: MACEDO, F. R. A. Felicidade pela educação: ensaios pedagógicos da Professora Annette Clotilde Macedo. Curitiba: Gerpa, 1952. p. 63-67.

MARTAGÃO GESTEIRA, R. Puericultura. Rio de Janeiro, Pan-Americana. In: AGUIAR, A.; MARTINS, R. M. (Org.). História da pediatria brasileira: coletânea de textos e depoimentos. Rio de Janeiro: Sociedade Brasileira de Pediatria \& Serviço de Informação Científica Nestlé, 1996.

MONCORVO FILHO, C. A. Histórico da proteção à infância no Brasil 15001922. Rio de Janeiro: Empresa Gráfica Editora Paulo Pongetti, 1927.

NERY, L. Patrícia Ilustre. 1928. In: MACEDO, F. R. A. Felicidade pela educação: ensaios pedagógicos da Professora Annette Clotilde Macedo. Curitiba: Gerpa, 1952. p. 147-148.

PYKOSZ, L. C. A higiene nos grupos escolares curitibanos: fragmentos da história de uma disciplina escolar (1917-1932). 2007. Dissertação (Mestrado em Educação) - Setor de Educação, Universidade Federal do Paraná, Curitiba, 2007.

ROCHA, S. M. M. O processo de trabalho em saúde e a enfermagem pediátrica: socialidade e historicidade do conhecimento. 1990. Tese (Livre docência) Escola de Enfermagem, Universidade de São Paulo, Ribeirão Preto, 1990.

ROCHA, S. M. M. Puericultura e enfermagem. São Paulo: Cortez, 1987.

SOCIEDADE DE SOCORRO AOS NECESSITADOS. Relatório oficial apresentado ao Conselho Deliberativo. Anos: 1929 e 1930.

TABORDA DE OLIVEIRA, M. A. (Org.). A educação do corpo na escola brasileira. Campinas: Autores Associados, 2006.

TURINA, K. F. R. Escola maternal: história, assistência e escolarização da infância em Curitiba (1928-1944). 2010. 127 f. Dissertação (Mestrado em Educação) Universidade Federal do Paraná, Curitiba, 2010. 
VILLELA, H. O. S. Da palmatória à lanterna mágica: a Escola Normal da Província Fluminense sob a direção de Alambary Luz (1868-1876). 2002. Tese (Doutorado em Educação) - Universidade de São Paulo, São Paulo, 2002.

Recebido: 28/07/2011

Received: 07/28/2011

Aprovado: 19/09/2011

Approved: 09/19/2011 